\title{
Experimental and computational study on the effect of ash deposition on fluid dynamic behavior in a bubbling fluidized bed gasifier
}

\author{
Rajan K Thapa Saroj Thapa Rajan Jaiswal Nora C I S Furuvik Britt M E Moldestad \\ Department of Process Energy and Environmental Technology, University of Southeastern Norway, Norway, \\ \{rajan.k.thapa, nora.c.i.furuvik, britt.moldestad\}@usn.no \\ 213843estudent.usn.no, rajanjaiswal357@outlook.com
}

\begin{abstract}
The effect of ash deposition on fluid dynamic behavior in a fluidized bed gasification reactor has been studied using experimental and computational methods. The experiments were carried out using sand particles as bed material and air as a fluidizing agent. A 3D computational model has been developed for a bubbling fluidized bed gasification reactor. First, the model was simulated using only sand particles and air. The results are compared with the experimental results. The comparison shows good agreement between the two sets of the results.

The model was further used to study the effect of ash accumulation on the fluid dynamic properties of a biomass gasification reactor. The bed material was mixed with 2 and $4 \mathrm{vol} \%$ of ash and simulated in cold conditions. Pressure drop increases and minimum fluidization velocity decreases with increasing the ash deposition in the bed. The model was also simulated for 2,4 , and 6 vol $\%$ of ash at a temperature of $800^{\circ} \mathrm{C}$. The minimum fluidization velocity was decreased in all the cases. The particle species concentration shows the ash particles start to segregate at the minimum fluidization condition and are totally separated at higher velocities. The bubble behavior of the bed is not effected by ash deposition.
\end{abstract}

Keywords: gasification, fluidized bed, segregation, mixing, CPFD, ash deposition

\section{Introduction}

\section{Background}

Gasification is the conversion of carbonaceous feedstock to the gaseous fuel by oxidation at a specific temperature. Gasification of biomass gives products such as carbon monoxide, hydrogen, and methane. The mixture of these gases is called producer gas.

Fluidized bed biomass gasification is a high temperature process where the producer gas is the main product and ash is a byproduct. In some cases, the gasification temperature can reach as high as the ash melting temperature causing the ash to melt inside the bed. This creates bed agglomeration and consequently defluidization of the reactor. Therefore, the ash melting phenomenon is undesirable in the gasification reactor.

Ash melting is also known as ash fusion or ash softening. This can also occur only in some of the hot spots in the bed. There are various reasons for the temperature to rise above the ash melting temperature. One of the reasons can be a high amount of ash deposition in the bed. Excessive ash deposition can reduce uniform mixing and heat transfer between bed material, biomass and fluidizing gas. The other reason can be the lower melting temperature of biomass ash which depends on its composition. Segregation between the deposited ash and bed material can also affect the mixing and heat transfer in the bed which can cause a rapid increase in temperature in some areas of the bed.

Many researchers have studied bed agglomeration in biomass gasification reactors. Bartels et al. have investigated the mechanism of agglomeration and concluded the fact that agglomeration takes place due to the adhesiveness of bed material caused by alkali compounds present in the biomass (Bartels et al., 2008). Pietsch (Pietsch, 2008) defined agglomeration as the formation of larger entities from particulate solid by sticking particles together by short range physical forces between the particles themselves, or through substances that adhere chemically or physically to the solid surface and form a material bridge between the particles. Visser and Tardos (Visser et al., 2008; Tardos et al., 1995) found two different routes for the initiation of bed agglomeration: melt-induced agglomeration and coating-induced agglomeration. Melt-induced means its adhesiveness with the bed particles that acts like glue. Coating-induced agglomeration implies the formation of coats between bed material and the liquid phase due to adhesive force or stickiness. Tardos and Pfeffer (Tardos, 1995) found that the fluidization behavior is changed according to the agglomeration of bed particles. The bubbling behavior can be useful to indicate the agglomeration in BFB (Montes, 2014).

A number of bubbles passing though the bed in a specific interval of time is known as the bubbling frequency. Generally, the bubbling frequency is the 
same in all sections of the bed, but the bubbling frequency becomes different due to agglomeration. The pressure drop through the bed is equal to the total hydrostatic pressure of the bed during the fluidizing condition. So, agglomeration of the fluidized bed is characterized by lower pressure drop (Montes et al., 2014; Furuvik et al., 2019).

Some of the significant elements in biomass ash are $\mathrm{K}$, $\mathrm{Na}, \mathrm{Ca}, \mathrm{Si}, \mathrm{P}, \mathrm{Mg}$, and $\mathrm{Al}$. In order to study the behavior of ash deposition in relation to the fluid dynamic behavior, and develop a computational model for ash, it is crucial to study physical properties such as density, particle size, sphericity and melting temperatures of these elements and the percentage of the major components in biomass ash. The study of the melting behavior and deposition of the ash are essential to make the biomass gasification reactor more efficient (Brown, 2005). Usually, high temperature is more favorable for carbon conversion because it produces less amount of tar. However, it brings other technological issues like ash melting and bed agglomeration (Niu et al., 2018). The alkali metals present in the biomass ash, will together with sulphur and chlorine in biomass fuels contribute to the bed agglomeration in fluidized bed reactors.

Biomass ash can be divided into three different groups based on their compositions. They are summarized in Table 1.

\begin{tabular}{|l|l|l|}
\hline Biomass ash group & $\begin{array}{l}\text { Ash } \\
\text { components }\end{array}$ & $\begin{array}{l}\text { Sintering } \\
\text { Temperature }\end{array}$ \\
\hline Woody biomass & $\begin{array}{l}\mathrm{Ca}, \mathrm{K} \text { rich } \\
\text { and Si lean }\end{array}$ & $900-1000^{\circ} \mathrm{C}$ \\
\hline $\begin{array}{l}\text { Rice husk, } \\
\text { bagasesses or reed } \\
\text { canary grass }\end{array}$ & $\begin{array}{l}\text { Si-rich , } \\
\mathrm{Ca}, \mathrm{K} \text { lean }\end{array}$ & $700-1000^{\circ} \mathrm{C}$ \\
\hline $\begin{array}{l}\text { Sunflower seed } \\
\text { and rapeseed seeds }\end{array}$ & $\begin{array}{l}\mathrm{Ca}, \mathrm{K} \text { and } \mathrm{P} \\
\text { rich }\end{array}$ & $700-1000^{\circ} \mathrm{C}$ \\
\hline
\end{tabular}

Table 1. Types of biomass ash (G. C. Institute. 2019)

The ash melting takes place due to the low melting point of components such as $\mathrm{K}, \mathrm{Na}$, and $\mathrm{S}$ that are present in woody biomass. The melted components start to bind together like glue and cause agglomeration of ash particles in the reactor (Vuthaluru et al., 1999). Bed agglomeration eventually causes de-fluidization which reduces the efficiency and might lead to a total shutdown of the bed. Moreover, ash deposition can cause corrosion in the reactor surface.

The studies are helpful for the prediction of ash melting and agglomeration of bed. The studies of the effect of the ash deposition on flow behavior in the fluidized bed reactor can prevent, in some cases, rising of the bed temperature above the ash melting temperature. Therefore, this work is focused on the ash deposition from woody biomass in fluidized bed gasification reactors and the effect of the ash deposition on the fluid dynamic behavior in the reactor.

\section{Experimental set up and procedure}

The arrangements of the experimental setup are shown in Figure 1.The setup consists of a $1.4 \mathrm{~m}$ long transparent column. The diameter of the column is 8.4 $\mathrm{cm}$. Pressure transducers are connected to the tapping points, which are located along with the height of the column. The tapping points are arranged along the column in different heights, and the distance between each tapping point is $10 \mathrm{~cm}$. At the bottom of the column, there is an air distributor. Compressed air is supplied from the bottom of the column, and the flow rate is is measured by a flow-measuring meter. The flow of the compressed air is controlled by valves. The particles were filled from the top of the column.
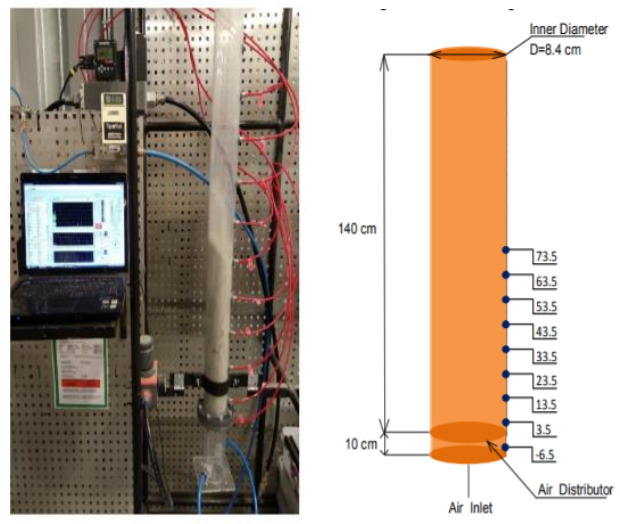

Figure 1. Experimental set up

The air flow rate and the pressure drop along the height of the column were logged in a LabView program. For each air velocity, data was recorded for more than 1 minute (sampling time $1 \mathrm{~s}$ ), and a minimum of the $60 \mathrm{~s}$ was allowed to establish the flow before the data was logged. Data Acquisition was done by Lab View, and the data was imported in MATLAB and used to plot the pressure drop against superficial gas velocity. The pressure drop can be calculated at each tapping point by subtracting the distributor pressure at a corresponding flow rate.

$\Delta \mathrm{P}_{\mathrm{f} 1}=\mathrm{P}_{\mathrm{f} 1}-\mathrm{D}_{\mathrm{f} 1}$

where $\Delta \mathrm{P}_{\mathrm{f} 1}$ is pressure reading at the pressure tapping point, $\mathrm{D}_{\mathrm{f} 1}$ is the distributor pressure and $\mathrm{P}_{\mathrm{f} 1}$ is the pressure at the pressure tapping point 1 .

The properties of bed material used in the experiments are given in Table 2.

Table 2. Properties of bed materials and fluidizing gas

\begin{tabular}{|l|c|}
\hline Particle mean diameter & $285 \mu \mathrm{m}$ \\
\hline Density & $2650 \mathrm{~kg} / \mathrm{m} 3$ \\
\hline Bulk density & $1428 \mathrm{~kg} / \mathrm{m} 3$ \\
\hline Solid volume fraction & 0.54 \\
\hline Air density & $1.25 \mathrm{~kg} / \mathrm{m} 3$ \\
\hline
\end{tabular}




\section{Computational model}

A Computational Particle Fluid Dynamic (CPFD) model have been implemented to simulate the gas-solid flow with heat transfer. The commercial CPFD software Barracuda VR 17 is used for the simulations. The CPFD numerical methodology incorporates the multi-phaseparticle-in-cell (MP-PIC) method. The gas phase is solved using Eulerian grid, and the particles are modeled as Lagrangian computational particles. Gas and particle momentum equations are solved in three dimensions. The fluid is described by the Navier-Stokes equation with strong coupling to the discrete particles. The particle momentum follows the MP-PIC description, which is a Lagrangian description of the particle motions described by ordinary differential equations with coupling with the fluid. More details about the computational methods are found in the literature (Andrews et al.,1996; Snider et al., 2001). The particles are grouped into parcels that contain a number of adjacent particles with similar properties such as density, size, species, and velocity. The parcels are called computational particles. The computational particle is a numerical approximation similar to the numerical control volume where a spatial region has a single property for the fluid. With these computational particles, large commercial systems containing billions of particles can be simulated using millions of computational particles. This possibility of the CPFD numerical method is used in this work to simulate the ash deposition in a fluidized bed with sand particles as bed material.

\subsection{Governing equations}

The gas phase mass and momentum conservation are modeled with continuity and time averaged NaiverStokes equations:

$$
\begin{aligned}
& \frac{\partial\left(\alpha_{g} \rho_{g}\right)}{\partial t}+\nabla \cdot\left(\alpha_{g} \rho_{g} u_{g}\right)=0 \\
& \begin{aligned}
\frac{\partial\left(\alpha_{g} \rho_{g} u_{g}\right)}{\partial t}+\nabla \cdot & \left(\alpha_{g} \rho_{g} u_{g} u_{g}\right) \\
& =-\nabla P+F+\nabla \cdot\left(\alpha_{g} \tau_{g}\right) \\
& +\alpha_{g} \rho_{g} g
\end{aligned}
\end{aligned}
$$

where, $\alpha_{g}, \rho_{g}$ and $u_{g}$ are gas phase volume fraction, density and velocity respectively. $\mathrm{F}$ is total momentum exchange with the particle phase per volume, $g$ is gravitational acceleration, $\mathrm{P}$ is the pressure and $\tau_{g}$ is the gas phase stress tensor, which is given by:

$\tau_{g}=\mu_{g}\left[\left(\nabla u_{g}+\Delta u_{g}^{T}\right)-\frac{2}{3} \nabla \cdot u_{g} I\right]$

$\mu_{g}$ refers to the shear viscosity that is the sum of the laminar and turbulent components. The large eddy simulation is used for the large-scale turbulence modeling while the subgrid scale turbulence is captured with Smagorinsky model:

$\mu_{g, t}=C_{s} \rho_{g} \Delta^{2}\left|\nabla u_{g}+\Delta u_{g}^{T}\right|$

Where $\Delta$ is the subgrid length scale and calculated by equation 5. The default value for the model constant $C_{s}$ is 0.01 .

$$
\Delta=(\delta x \delta y \delta z)^{1 / 3}
$$

The interface momentum transfer is calculated through the viscous drag force:

$$
F=\iint f\left\{m_{p}\left[D_{p}\left(u_{g}-u_{p}\right)-\frac{\nabla P}{\rho_{p}}\right]\right\} d m_{p} d u_{p}
$$

Subscript $\mathrm{p}$ refers to the particle phase properties where $\mathrm{m}$ and $\mathrm{u}$ symbolize the mass and velocity. $D_{p}$ is the drag function. The particle phase dynamics are derived using particle distribution function (PDF) calculated from the Liouville equation given as:

$\frac{\partial f}{\partial t}+\nabla\left(f u_{p}\right)+\nabla u_{p}\left(f A_{p}\right)=0$

where $A_{p}$, is the particle acceleration and is expressed by:

$A_{p}=\frac{\partial\left(u_{p}\right)}{\partial t}=D_{p}\left(u_{g}-u_{p}\right)-\frac{\nabla P}{\rho_{p}}-\frac{\nabla \tau_{p}}{\rho_{p} \alpha_{p}}+g$

$\alpha_{p}$ is particle volume fraction and $\tau_{p}$ is particle stress function that is used in formulating interphase interactions of particles.

$$
\begin{aligned}
& \alpha_{p} \\
& =\iint f \frac{m_{p}}{\rho_{p}} d m_{p} d u_{p} \\
& \tau_{p} \\
& =\frac{10 P_{s} \alpha_{p}^{\beta}}{\max \left[\left(\alpha_{c p}-\alpha_{p}\right), \varepsilon\left(1-\alpha_{p}\right)\right]}
\end{aligned}
$$

$P_{S}$ is a constant with the units of pressure, $\alpha_{c p}$ is the particle volume fraction at close packing, $\beta$ is a constant between 2 and 5 where $\varepsilon$ is a very small number on the order of 10-7.

\subsection{Model parameters and geometry}

A cylindrical CAD geometry with a height of $1.4 \mathrm{~m}$ and diameter $8.4 \mathrm{~cm}$ was imported in Barracuda VR. The geometry is divided into 8652 uniform grids. After the grid generation, the base materials, the particle species, the pressure boundary condition, and the flow boundary condition were specified in Barracuda, which are similar to the experimental settings. The grid and boundary conditions are shown in Figure 2. No particle exit was considered during the simulation. The pressure monitoring points were selected $3.5 \mathrm{~cm}, 13.5 \mathrm{~cm}$, and 
$23.5 \mathrm{~cm}$ along the height of the bed as in the experiments.

In Figure 2, the top of the cylinder yellow colored) is a pressure outlet boundary and the bottom of the reactor (red colored) is a velocity inlet boundary. The particles and gas are used similar to the experiments. The simulations were run in a cold bed as well as in hot bed conditions to analyze the flow properties in a real bed with various volume percent of ash deposition.

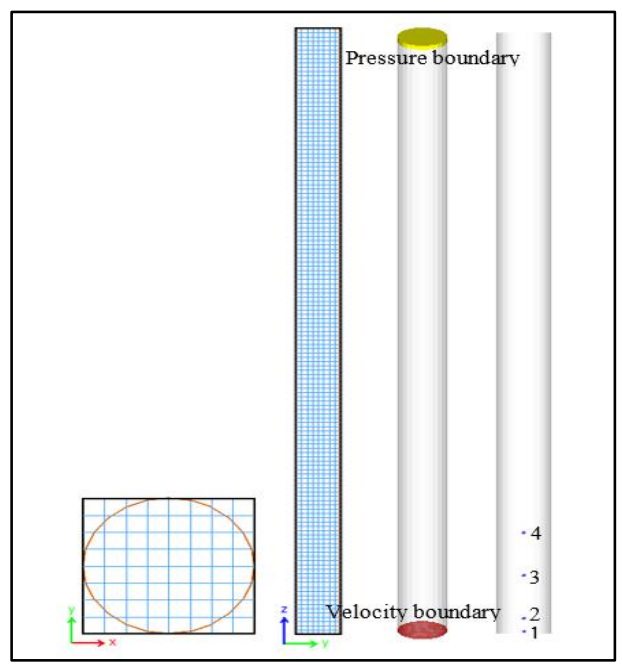

Figure 2. Grid and boundary conditions

The Wen-Yu drag model was used with $60 \%$ momentum loss after the particle collision. The initial height of the bed was $21 \mathrm{~cm}$, which gives the bed aspect ratio (ratio of height to diameter) of 2.5. The initial time step was taken as $0.001 \mathrm{~s}$. Initial particle volume fraction was taken as 0.54 . The simulations were performed for 120 s of simulation time. Simulations were run for several air velocities and with different volume percent of ash mixed with sand particles to analyze the flow properties variation with the ash deposition.

Therefore, only the major elements of the ash composition were taken for the model. The composition and properties of ash particles used in the model are presented in Table 2.

Table 2. Properties biomass ash

\begin{tabular}{|l|l|}
\hline $\mathrm{SiO} 2$ & $\begin{array}{l}30 \% \text { of total ash } \\
\text { components }\end{array}$ \\
\hline $\mathrm{K} 2 \mathrm{O}$ & $17 \%$ \\
\hline $\mathrm{CaO}$ & $53 \%$ \\
\hline Average density & $2959 \mathrm{Kg} / \mathrm{m} 3$ \\
\hline Molar mass & $63.75 \mathrm{~g} / \mathrm{mol}$ \\
\hline Particle Size & $50 \mu \mathrm{m}$ \\
\hline Solid volume fraction & 0.6 \\
\hline Sphericity & 0.7 \\
\hline
\end{tabular}

The minor components of the ash are neglected, and the density and molar mass of the ash are calculated according to the densities and molar masses of the major components.

\section{Results and discussion}

\subsection{Experimental results}

A series of the experiments were carried out with different superficial air velocities, and the pressure drop along the height of the bed was calculated using the experimental data. The plot of the pressure drop as a function of superficial velocities (Figure 3) shows that the minimum fluidization velocity for sand particles is $0.075 \mathrm{~m} / \mathrm{s}$ and the pressure drop at the minimum fluidization velocity is $13084 \mathrm{~Pa} / \mathrm{m}$.

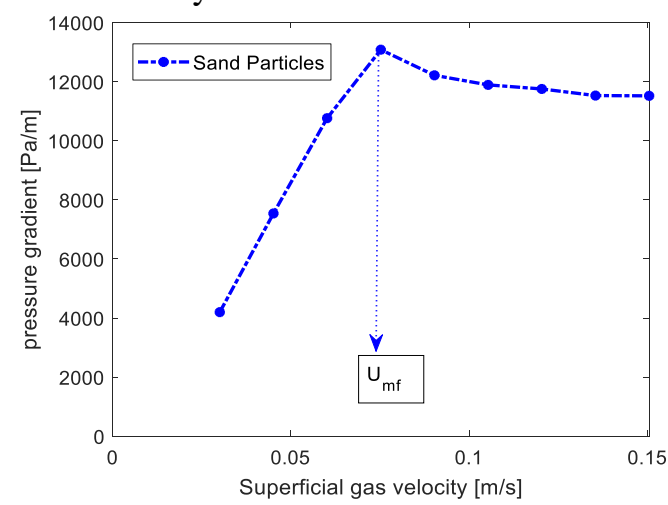

Figure 3. Pressure drop vs. superficial air velocity It was difficult to run an experiment with a mixture of sand particles and ash because the ash particles are very small and fine particles, which could leave the reactor. It was actually the main reason for developing the CPFD model and simulating the flow of sand particles with ash.

\subsection{Computational results}

Simulations were run for the bed with sand particles, which is exactly similar to the experimental condition. The simulation results are compared against the experimental. Figure 4 shows a comparison of experimental and computational pressure drops along the bed and the minimum fluidization velocity of the bed.

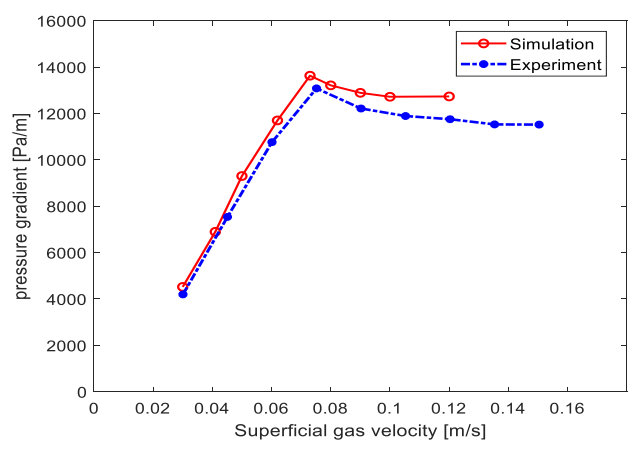

Figure 4. Comparison of pressure drop and minimum fluidization velocities 
The figure shows good agreements between the experimental and computational results. The pressure drop and minimum fluidization velocities are almost similar in both cases. The aim of this comparison was to validate a CPFD model for its further use for simulation of a bed with various volume percent of ash deposition. Therefore, a series of the simulation were run to simulate the bed of sand particles with $2 \%$ and $4 \mathrm{vol} \%$ of ash particles by volume. The simulations were run for cold conditions at room temperature.

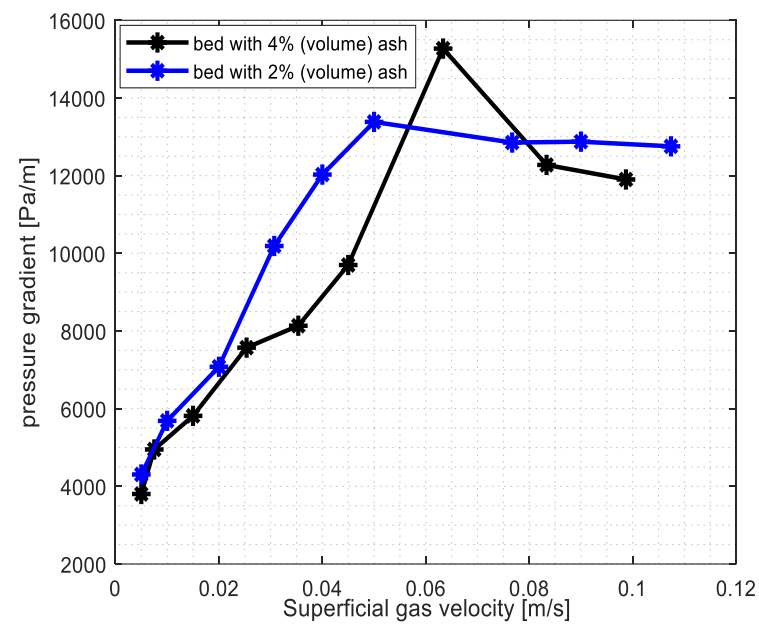

Figure 5. Minimum fluidization velocities for the mixture of ash with sand.

The pressure drop is increased with increasing ash volume percentage. The minimum fluidization velocities increased with increasing volume percent of ash, as shown in Figure 5. Minimum fluidization velocity for beds of small particles is strongly depended on bed void fraction [13], which can be seen from the equation:

$u_{m f}=\frac{d_{p}^{2}\left(\rho_{p}-\rho_{g}\right) g}{150 \mu} \cdot \frac{\varepsilon_{m f}^{3} \phi_{s}^{2}}{1-\varepsilon_{m f}}$

where, $d_{p}$ is particle diameter, $\rho_{p}$ and $\rho_{g}$ are particle and gas densities, $\varepsilon_{m f}$ is bed void fraction, $\phi_{s}$ is sphericity and $\mu$ is gas viscosity. Presence of ash particles which have small particle size compared to the sand having larger particles size makes ash particles to fill the void between the sand particles reducing the void fraction in the bed. This is the reason for the reduction of minimum fluidization velocity. This means a limited ash deposition in the bed does not have negative impact in flow properties (particularly in fluidization velocity) before the sand particles are segregated in the bed.

Simulations were also run at high temperature. Figure 6 shows the simulation results at the temperature of $800^{\circ} \mathrm{C}$. The bed was mixed with sand particles and $2 \%$, $4 \%$ and $6 \%$ by volume of ash particles. The results show that an increase in the temperature decreases the minimum fluidization velocities. When the temperature of fluidizing air is increased from $20^{\circ} \mathrm{C}$ to $800^{\circ} \mathrm{C}$, the viscosity of air increases from $1.825 \cdot 10^{-5} \mathrm{~Pa} \cdot \mathrm{s}$ to
$4.362 \cdot 10^{-5} \mathrm{~Pa} \cdot \mathrm{s}$. The increase in viscosity is the reason for the decrease in minimum fluidization velocity (See equation 12). The results show that the ash deposition up to $6 \%$ by volume has no negative effect on the flow behavior in the reactor. However, the pressure drop in the bed increases with increasing ash deposition. The deposition will have negative effect only when the temperature of any spot of the bed reaches the ash melting temperature. In order to avoid this, it is important to enhance the mixing of particles in bed and avoid segregation.

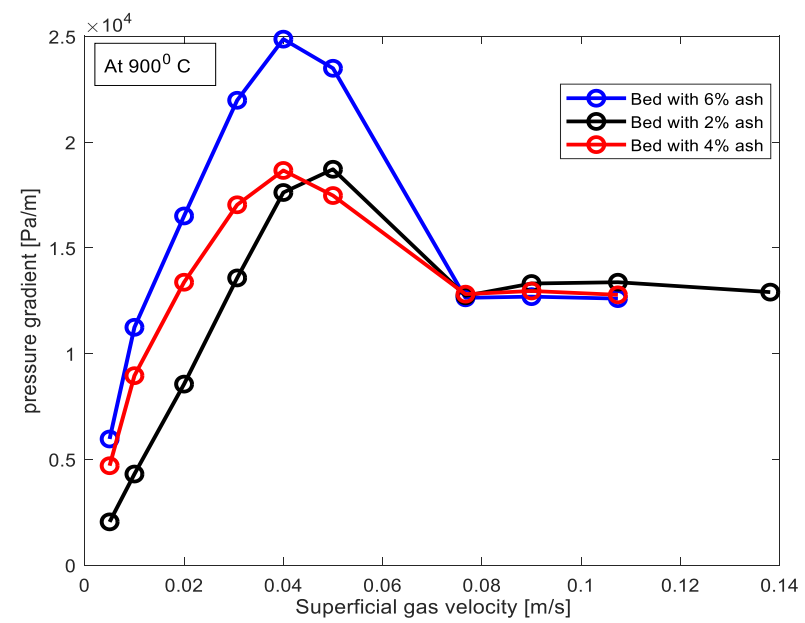

Figure 6. Minimum fluidization velocity at high temperature conditions.

The CPFD model allows tracking the particles in the bed separately in the form of different particle species. The distribution of ash and sand particles in the bed are shown in Figure 7. The figure shows the comparison of species distribution in the bed at the minimum fluidization velocity and the air velocity of $0.21 \mathrm{~m} / \mathrm{s}$ for the bed with 2, 4 and 6 vol\% ash respectively from left to right.

The figure shows that a part of the ash particles have segregated and moved to the top of the bed already at the minimum fluidization condition and the segregation becomes more distinct at the higher air velocities.

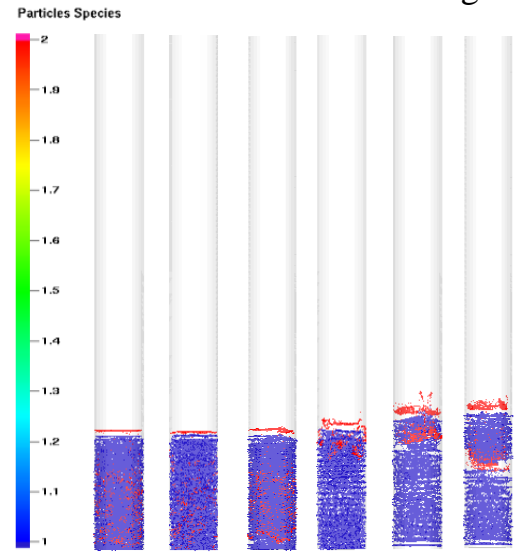

Figure 7. Sand and ash particle species distribution in the bed

Deposited ash, after segregation can effect negatively on the mixing and heat transfer in the bed. This is more 
probable at the top of the bed where only ash particles are present. This can create hot spots in the upper part of the bed.

The bubble behavior in the bed at the air velocity of 0.21 $\mathrm{m} / \mathrm{s}$ are shown in Figure 8 . The figure shows that there is no significant effect of the ash deposition on the bubble properties in the middle and the lower part of the bed. The reason can be that the ash particles are segregated and move to the top of the bed and only the sand particles, part of biomass and the air are involved in the bed which does not hinder bubble formation and growth along with the height of the bed.
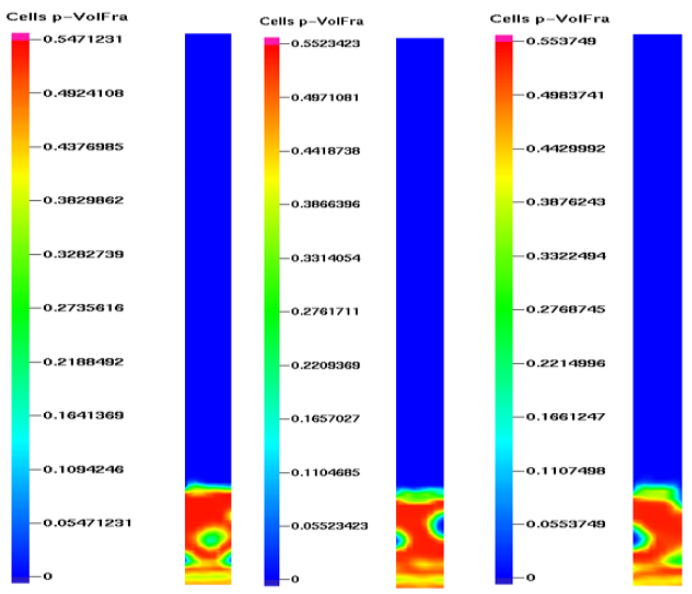

Figure 8. Bubble in the bed at an air velocity of $0.21 \mathrm{~m} / \mathrm{s}$ for $2 \%, 4 \%$ and $6 \%$ of ash from left to right

\section{Conclusion}

A CPFD model is developed for the study of 3D flow in a bubbling fluidized bed biomass gasification reactor. The model is validated against the experimental measurements in a cold flow model of the reactor. The results give good agreement between experiments and model predictions. The valid model is used to study the effect of ash deposition on the flow behavior of the reactor in cold and hot bed conditions.

The minimum fluidization velocities are decreased with increasing volume percent of ash in the bed under cold bed conditions. However, the pressure drop is increased. The minimum fluidization velocity is further reduced at a high temperature.

The ash particles start to segregate from the minimum fluidization condition moving towards the top of the bed, and the segregation is increasing with increasing air velocity. However, the bubble behavior in the bed remains the same with increasing ash volume percent in the bed.

\section{References}

M.J. Andrews and P.J. O'Rourke. The multiphase particleincell (MP-PIC) method for dense particle flow. International Journal of Multiphase Flow, 22:379-402, 1996. https://doi.org/10.1016/0301-9322(95)00072-0

M. Bartels, W. Lin, J. Nijenhuis, F. Kapteijn, and J. R. Van Ommen. Agglomeration in fluidized beds at high temperatures: Mechanisms, detection and prevention, Progress in Energy and Combustion Science, 34(5):633666, 2008. https://doi.org/10.1016/j.pecs.2008.04.002

G. Brown, A. Hawkes, A. Bauen, and M. Leach. 1. Biomass Applications, Centre for Energy Policy and Technology, Imperial College, 2005.

K. Daizo and O. Levenspiel. Fluidization Engineering. Butterworth-Heinemann, USA, 1991.

N. C. Furuvik, R. Jaiswal, and B. M. Moldestad. Flow behavior in an agglomerated fluidized bed gasifier," International Journal of Energy and Environment, 10(2): 55-64, 2019.

C. Institute. G (, ACN: 136814 465.ABN: 92136814 465). Combustion of different types of biomass [Online]. Available: https://hub.globalccsinstitute.com/publications/biomassccs-study combustion-different-types-biomass.

A. Montes. Factors Affecting Bed Agglomeration in Bubbling Fluidized Bed Biomass Boilers, Masters thesis, School of graduate and post graduate studies, The university of western Ontario, 2014.

M. Niu, Q. Dong, Y. Huang, B. Jin, H. Wang, and H. Gu. Characterization of ash melting behaviour at high temperatures under conditions simulating combustible solid waste gasification, Waste Management \& Research, 36(5): 415-425, 2018. https://doi.org/10.1177/0734242X18763064

W. B. Pietsch. Agglomeration processes: phenomena, technologies, equipment. John Wiley \& Sons, 2008.

D.M. Snider. An Incompressible Three-Dimensional Multiphase Particle-in-Cell Model for Dense Particle Flows. Journal of Computational Physics, 2001. 170(2):523549. https://doi.org/10.1006/jcph.2001.6747

G. Tardos and R. Pfeffer. Chemical reaction induced agglomeration and defluidization of fluidized beds, Powder Technology, 85(1):29-35, 1995. https://doi.org/10.1016/ 0032-5910(95)03002-Q

H. S. Visser, C. van Lith, and J. Kiel. Biomass ash-bed material interactions are leading to agglomeration in FBC, Journal of Energy Resources Technology, vol. 130, no. 1, p. 011801, 2008. doi.10.1016/j.apenergy.2016.05.063

H. Vuthaluru, T. M. Linjewile, D.-k. Zhang, and A. Manzoori. Investigations into the control of agglomeration and defluidisation during fluidised-bed combustion of low-rank coals, Fuel, vol. 78, no. 4, pp. 419-425, 1999. https://doi.org/10.1016/S0016-2361(98)00165-3 